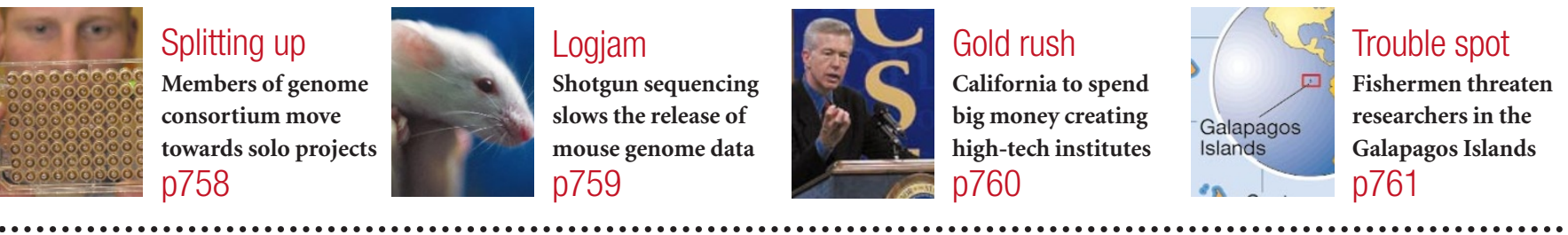

\title{
Japan to bypass bureaucracy by reshaping science ministries
}

David Cyranoski and Robert Triendl, Tokyo

Japanese science policy faces a huge shakeup next year, as the government bids to curtail the influence of its own bureaucrats. On 6 January, two new official bodies will come into operation as part of the most comprehensive reorganization of the Japanese government since 1945.

The Council for Science and Technology Policy (CSTP) will oversee science policy, and the Ministry of Education, Culture, Sports, Science and Technology will be in charge of both education and most of Japan's public research and development funding. The government is set to follow the changes with a shake-up of the national laboratories in April.

Takashi Sasagawa, a wealthy legislator, was named last week as the minister for the CSTP, which supersedes the existing Council for Science and Technology. According to Naoko Okamura, deputy director of the council's secretariat, the CSTP will be responsible for general policy coordination, budget oversight and evaluation.

But some worry that Sasagawa, who has

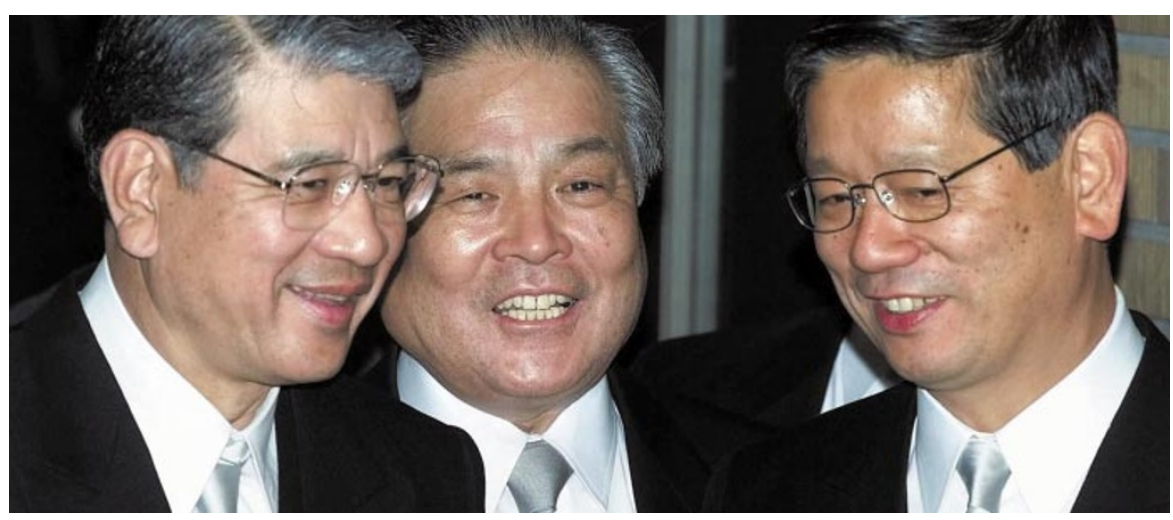

New brooms: Sasagawa (left) and Machimura (right) will take charge of Japan's science policy.

been embroiled in a tax-evasion scandal, may lack the clout to tackle these issues - and that his post may not survive the next cabinet reshuffle.

In the past, the council was unable to coordinate policy effectively because it was viewed as part the Science and Technology Agency (STA) - one of the agencies competing for funds - which provided it with

\section{Germany sets up electronic archive}

\section{Quirin Schiermeier, Munich}

In response to complaints from researchers about the cost of scientific journals,

Germany's largest network of laboratories plans to build a standardized desktop information system for all its scientists.

The Max Planck Society (MPS) has created a Centre for Information Management in Garching, near Munich. Its role will be to enable scientists at its 78 laboratories to publish their work in openaccess electronic repositories.

When the centre opens next month, its managers will decide whether the MPS should operate its own server, or get involved in similar initiatives elsewhere. These include E-BioSci, a publication server for the life sciences managed by the European Molecular Biology Laboratory, and PubMed Central, a similar project run by the US National Institutes of Health.
But the centre's main partner will initially be the Los Alamos National Laboratory in the United States, whose e-print archives are the primary means of electronic communication in areas such as high-energy physics, maths and computer science. Richard Luce, head of Los Alamos' 'Library Without Walls' project - which provides digital library resources - is advising the new centre.

There is also concern that German scientists have been generally slow to respond to the information revolution. "No one is forging a clear path," says Robert Schlögl, scientific director at the Berlinbased Fritz Haber Institute and a member of the MPS steering group on electronic information. "If we let these developments pass us by, we will end up completely dependent on US technologies." http://www.mpg.de/it/cim/director.html administrative support.

It has been suggested that the nowindependent council will oversee special programmes, such as last year's Millennium Project (see Nature 401, 3; 1999). The council is certain to play an important part in selecting future research initiatives.

Nozomi Sagara, a deputy director of the research planning division at the Agency of Industrial Science and Technology, says that although the council will not supervise agencies or ministries directly, it will set out policies for them to follow.

Akiyoshi Wada, director of the RIKEN Genomic Sciences Center, one of the STA's largest research institutes, thinks that the new arrangement will help to encourage long-term basic research. "Everybody is thinking about tomorrow, but never the day after tomorrow," he says.

The Ministry of Education, Culture, Sports, Science and Technology will be headed by Nobutaka Machimura, a legislator with close ties to the prime minister. The ministry will control about two-thirds of Japan’s $¥ 3.3$ trillion (US\$30 billion) annual research and development budget.

There is some concern among former STA officials and in the scientific community that the traditionally conservative education ministry will put the brakes on more adventurous research programmes. STA officials also worry that funds needed to refurbish Japan's ailing national universities — around $¥ 3$ trillion — will be diverted from STA research projects. 